\title{
Fate of Cu, Cr and As During Combustion of Impregnated Wood with and without Peat Additive
}

\author{
Karin Lundholm ${ }^{\mathrm{a} *}$, Dan Boström ${ }^{\mathrm{a}}$, Anders Nordin ${ }^{\mathrm{a}}$, Andrei Shchukarev ${ }^{\mathrm{b}}$ \\ ${ }^{a}$ Energy Technology and Thermal Process Chemistry, Umeå University, SE-901 87 Umeå, Sweden \\ ${ }^{\mathrm{b}}$ Inorganic Chemistry, Umeå University, SE-901 87 Umeå, Sweden
}

\section{Contents}

Table SI 1 Chemical composition of the CCA-wood and the fuel blends. Values in moles per $1000 \mathrm{~kg}$ fuel.

Figure SI 1 Calculated distributions of $\mathrm{Cu}$ (top), $\mathrm{Cr}$ (middle) and As (bottom) for CCA-wood co-combusted with Norrheden peat (20\% CCA, $80 \%$ peat) in the combustion zone.

Figure SI 2 Calculated distributions of $\mathrm{Cu}$ (top), $\mathrm{Cr}$ (middle) and As (bottom) for CCA-wood co-combusted with Omberg peat (20\% CCA, $80 \%$ peat) in the combustion zone.

Figure SI 3 Calculated distributions of copper (top), chromium (middle), and arsenic (bottom) compounds for co-combustion of $50 \%$ CCA-wood and $50 \%$ Norrheden peat in the flue gas zone.

Figure SI 4 Calculated distributions of copper (top), chromium (middle), and arsenic (bottom) compounds for co-combustion of $20 \%$ CCA-wood and $80 \%$ Norrheden peat in the flue gas zone.

Figure SI 5 Calculated distributions of copper (top), chromium (middle), and arsenic (bottom) compounds for co-combustion of 50 \% CCA-wood and $50 \%$ Omberg peat in the flue gas zone.

Figure SI 6 Calculated distributions of copper (top), chromium (middle), and arsenic (bottom) compounds for co-combustion of $20 \%$ CCA-wood and $80 \%$ Omberg peat in the flue gas zone.

Figure SI $7 \quad$ Particle mass size distributions for different fuels. 


\section{Supporting Information for manuscript es0630689}

Table 1. Chemical composition of the CCA-wood and the fuel blends. Values in moles per $1000 \mathrm{~kg}$ fuel.

\begin{tabular}{lccccc}
\hline CCA & $\begin{array}{l}\text { CCA/ } \\
\text { Norrheden } \\
50 / 50\end{array}$ & $\begin{array}{l}\text { CCA/ } \\
\text { Norrheden } \\
20 / 80\end{array}$ & $\begin{array}{l}\text { CCA/ } \\
\text { Omberg } \\
50 / 50\end{array}$ & $\begin{array}{l}\text { CCA/ } \\
\text { Omberg } \\
20 / 80\end{array}$ \\
\hline $\mathrm{C}$ & 42700 & 43100 & 43900 & 42900 & 43500 \\
$\mathrm{H}$ & 60200 & 59600 & 58400 & 59600 & 57900 \\
$\mathrm{O}$ & 25900 & 25000 & 23600 & 25500 & 24200 \\
$\mathrm{~N}$ & 95.2 & 288 & 687 & 150 & 366 \\
$\mathrm{~S}$ & 4.16 & 19.2 & 37.9 & 19.0 & 59.8 \\
$\mathrm{Cl}$ & 2.85 & 3.18 & 3.71 & 3.20 & 3.95 \\
$\mathrm{~K}$ & 5.49 & 5.23 & 4.76 & 5.63 & 5.09 \\
$\mathrm{Na}$ & 0.678 & 1.21 & 2.00 & 1.29 & 2.67 \\
$\mathrm{Ca}$ & 18.6 & 43.1 & 74.7 & 46.1 & 117 \\
$\mathrm{Al}$ & 1.89 & 18.1 & 40.1 & 2.01 & 13.7 \\
$\mathrm{Fe}$ & 1.74 & 20.4 & 45.3 & 2.05 & 15.2 \\
$\mathrm{Si}$ & 4.41 & 24.4 & 50.9 & 6.38 & 29.8 \\
$\mathrm{Cu}$ & 13.5 & 12.5 & 10.3 & 13.5 & 10.1 \\
$\mathrm{Cr}$ & 1.95 & 2.37 & 1.06 & 1.82 & 3.73 \\
$\mathrm{As}$ & 18.4 & 16.8 & 14.4 & 19.2 & 13.9 \\
\hline
\end{tabular}


Supporting Information for manuscript es0630689

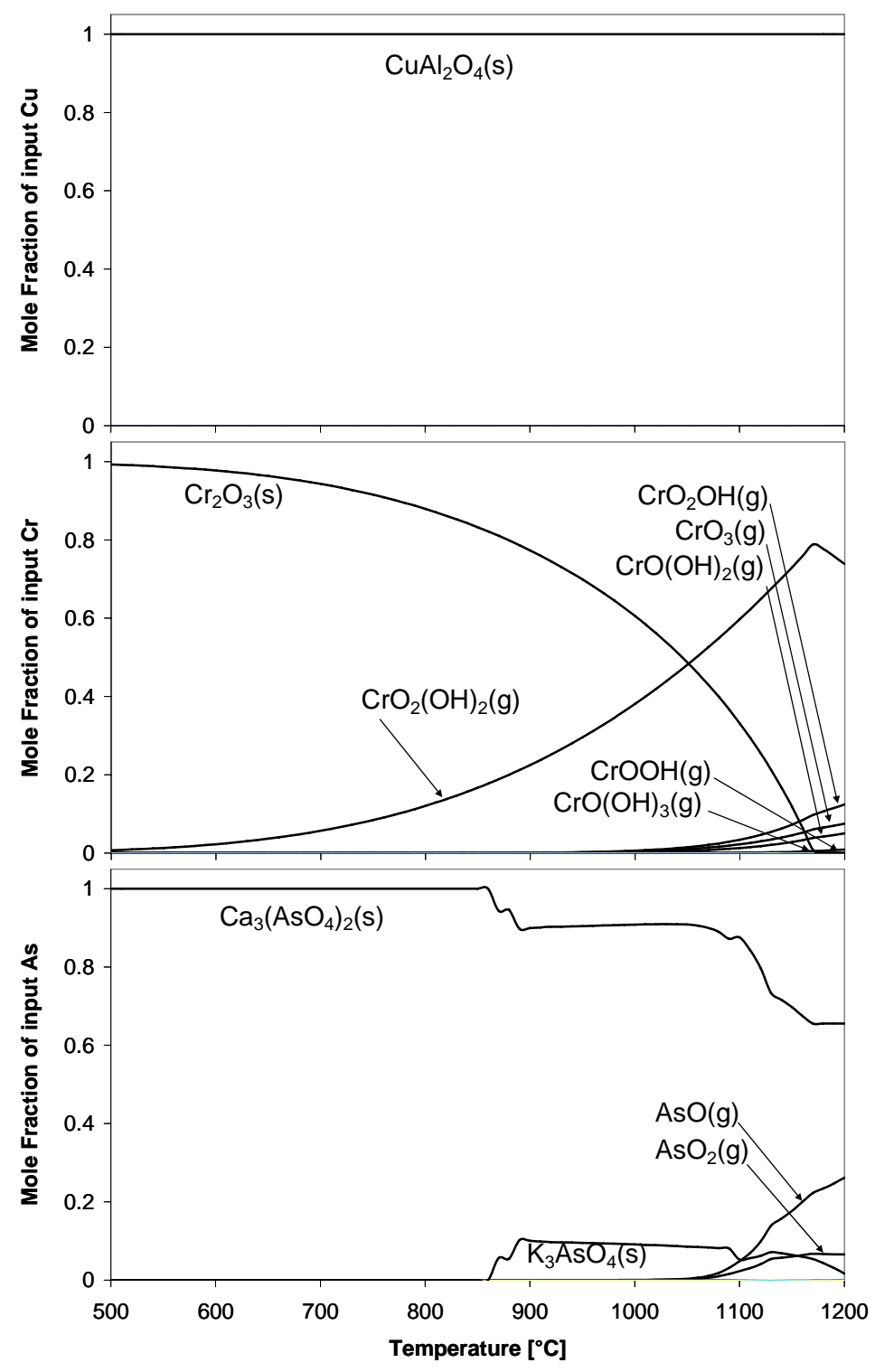

Figure SI 1. Calculated distributions of $\mathrm{Cu}$ (top), $\mathrm{Cr}$ (middle) and As (bottom) for CCA-wood co-combusted with Norrheden peat ( $20 \%$ CCA, $80 \%$ peat) in the combustion zone. 
Supporting Information for manuscript es0630689

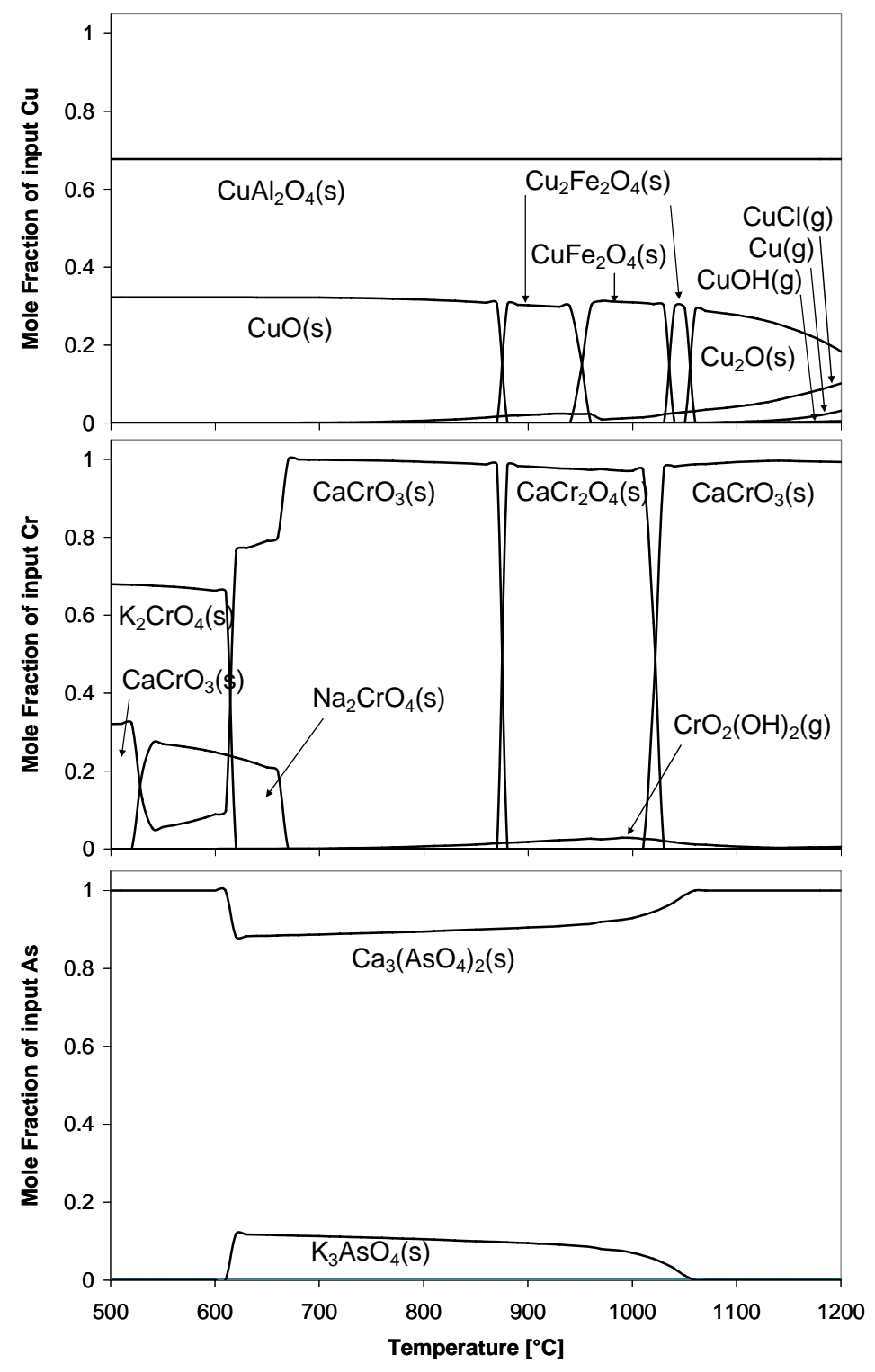

Figure SI 2. Calculated distributions of $\mathrm{Cu}$ (top), $\mathrm{Cr}$ (middle) and As (bottom) for CCA-wood co-combusted with Omberg peat ( $20 \%$ CCA, $80 \%$ peat) in the combustion zone. 


\section{Supporting Information for manuscript es0630689}
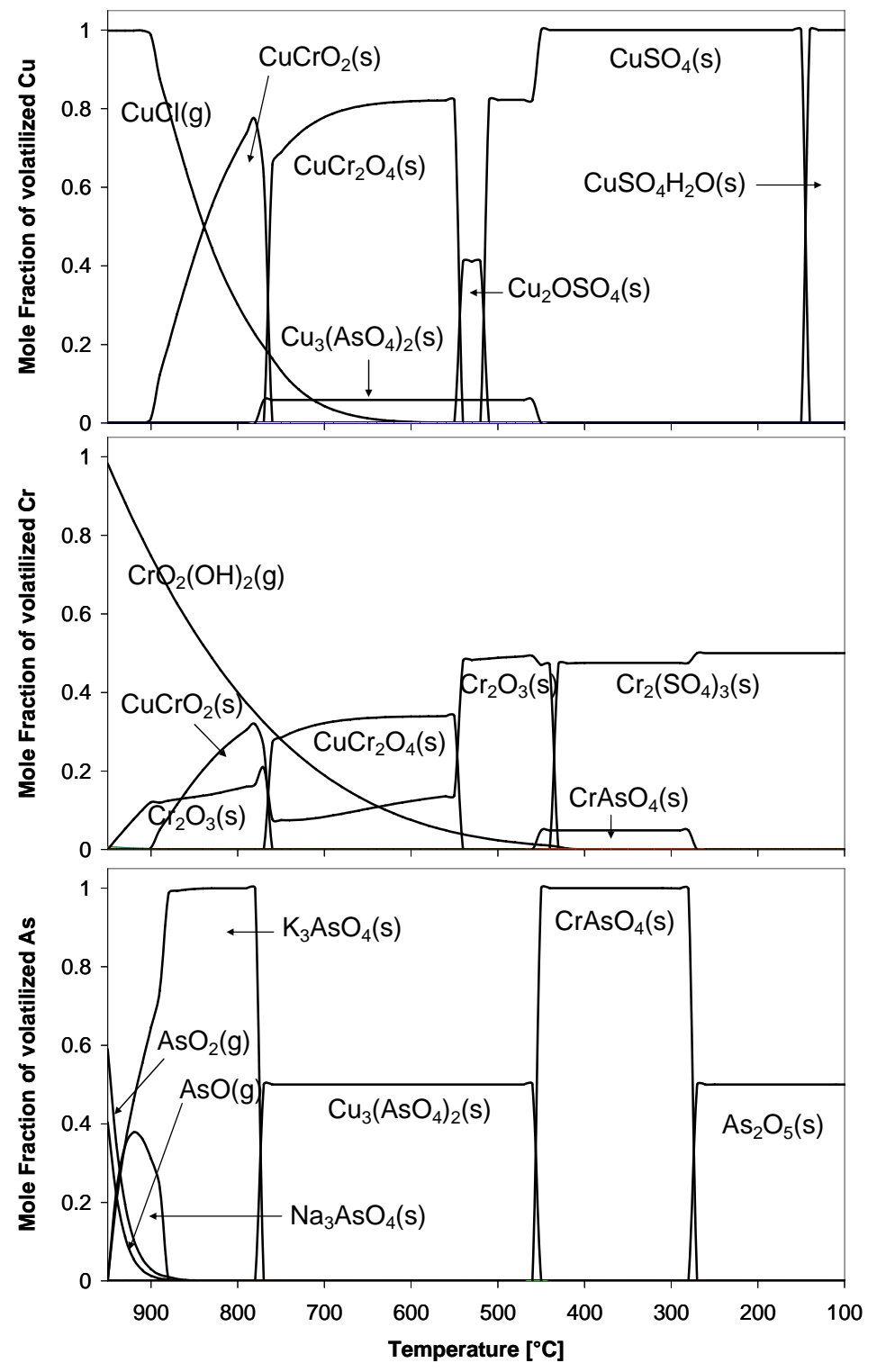

Figure SI 3. Calculated distributions of copper (top), chromium (middle), and arsenic (bottom) compounds for co-combustion of 50 \% CCA-wood and 50 \% Norrheden peat in the flue gas zone. 


\section{Supporting Information for manuscript es0630689}
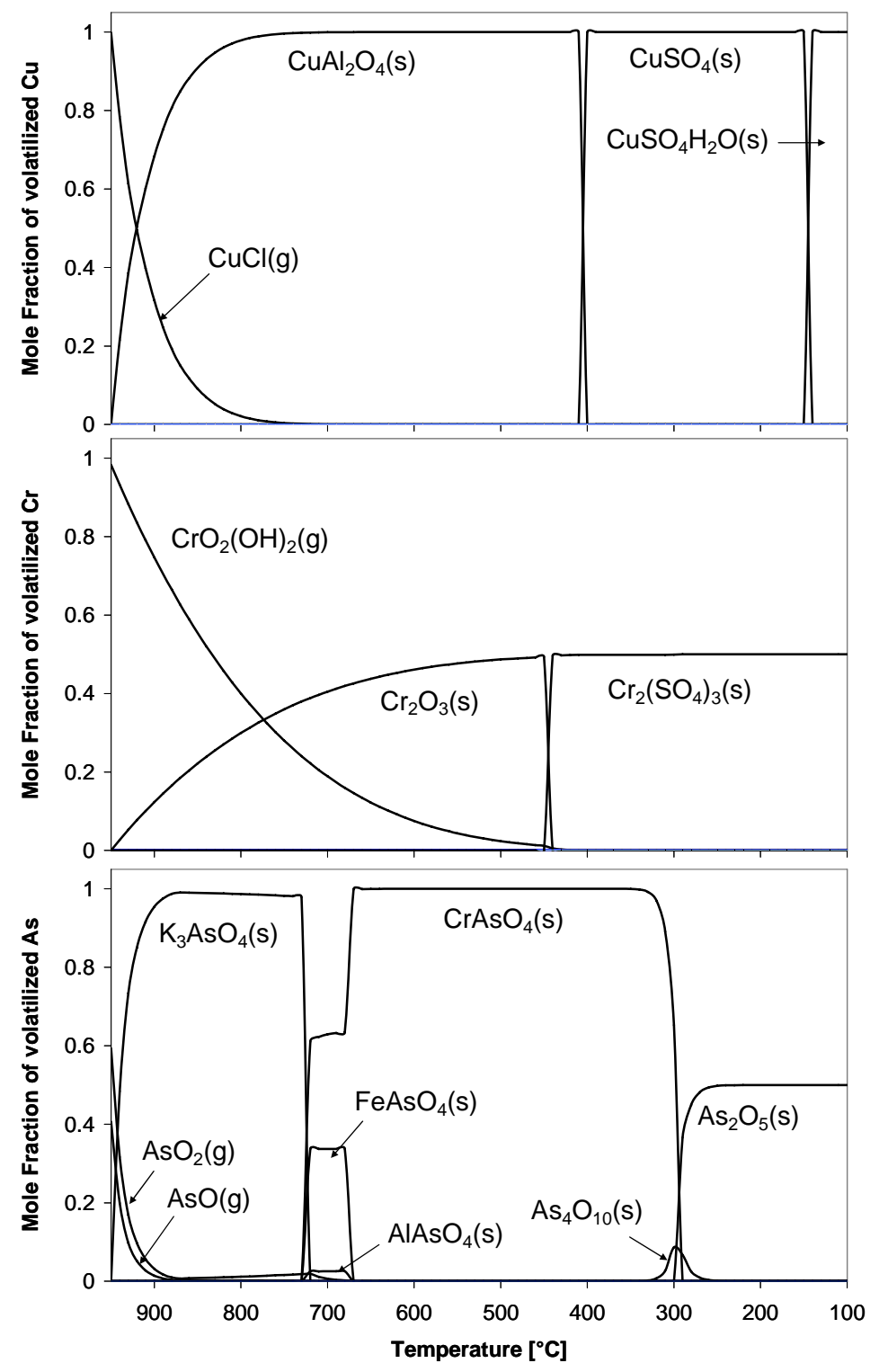

Figure SI 4. Calculated distributions of copper (top), chromium (middle), and arsenic (bottom) compounds for co-combustion of 20 \% CCA-wood and 80 \% Norrheden peat in the flue gas zone. 


\section{Supporting Information for manuscript es0630689}

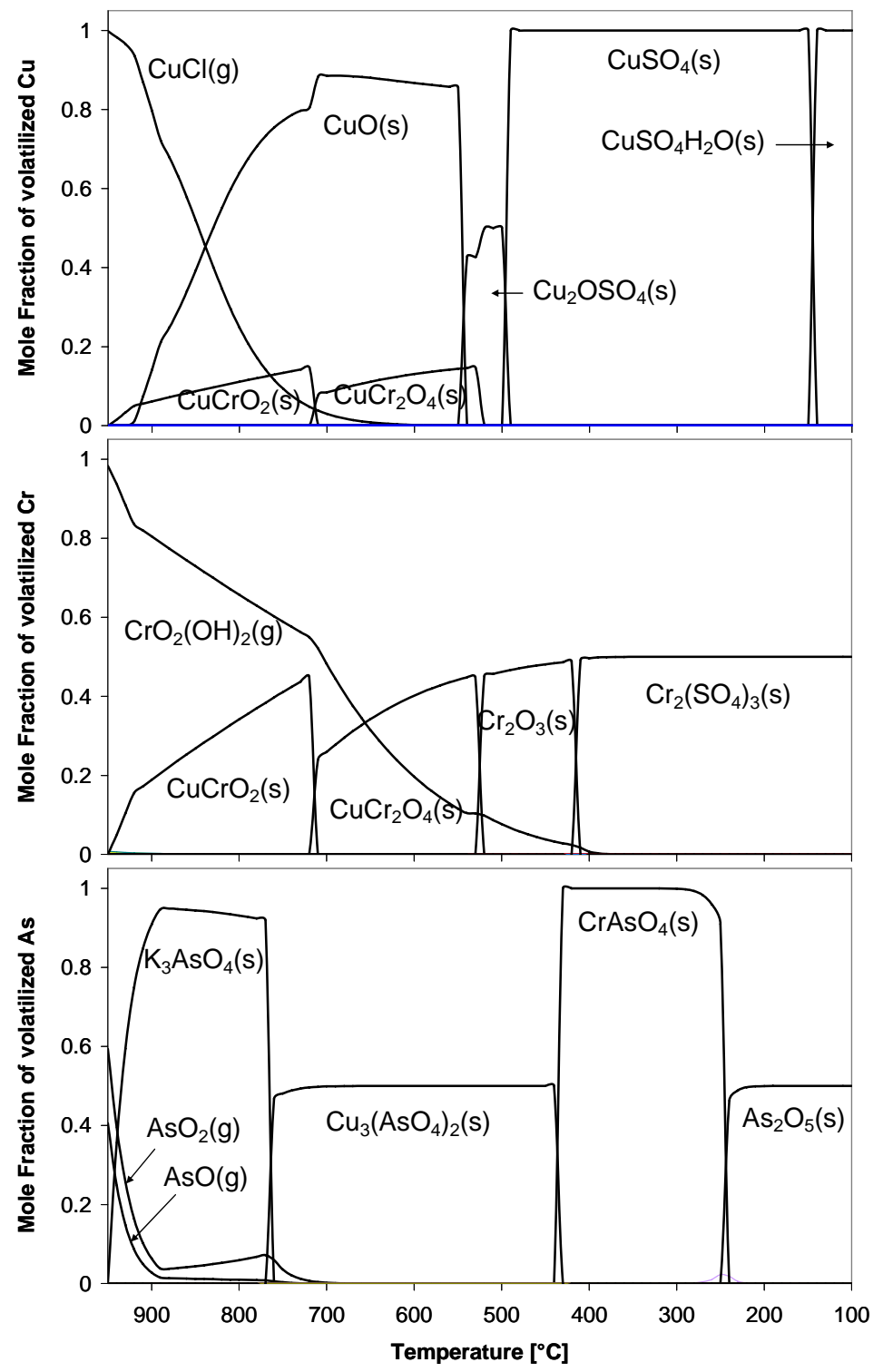

Figure SI 5. Calculated distributions of copper (top), chromium (middle), and arsenic (bottom) compounds for co-combustion of 50 \% CCA-wood and 50 \% Omberg peat in the flue gas zone. 


\section{Supporting Information for manuscript es0630689}
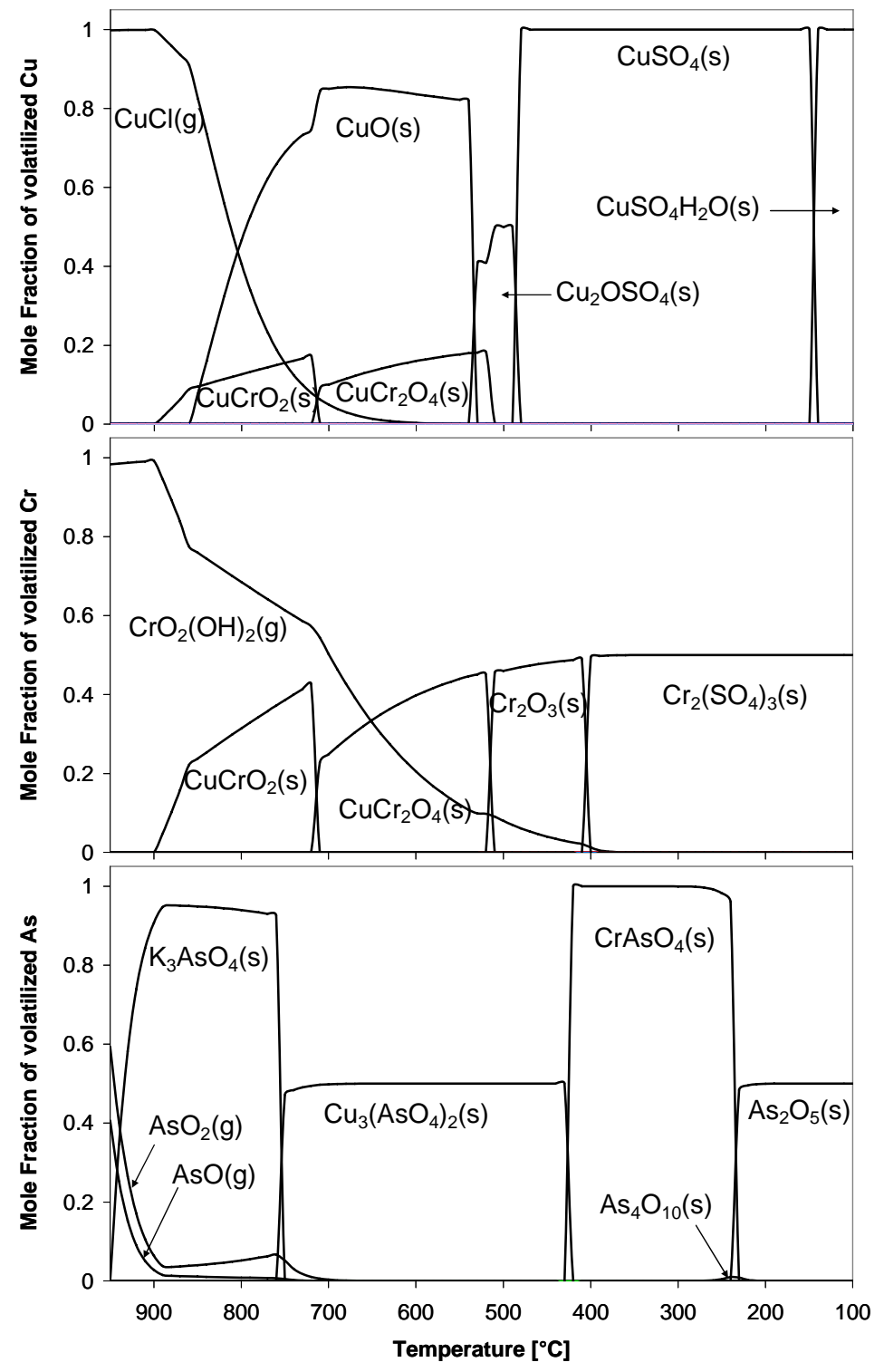

Figure SI 6. Calculated distributions of copper (top), chromium (middle), and arsenic (bottom) compounds for co-combustion of $20 \%$ CCA-wood and $80 \%$ Omberg peat in the flue gas zone. 
Supporting Information for manuscript es0630689

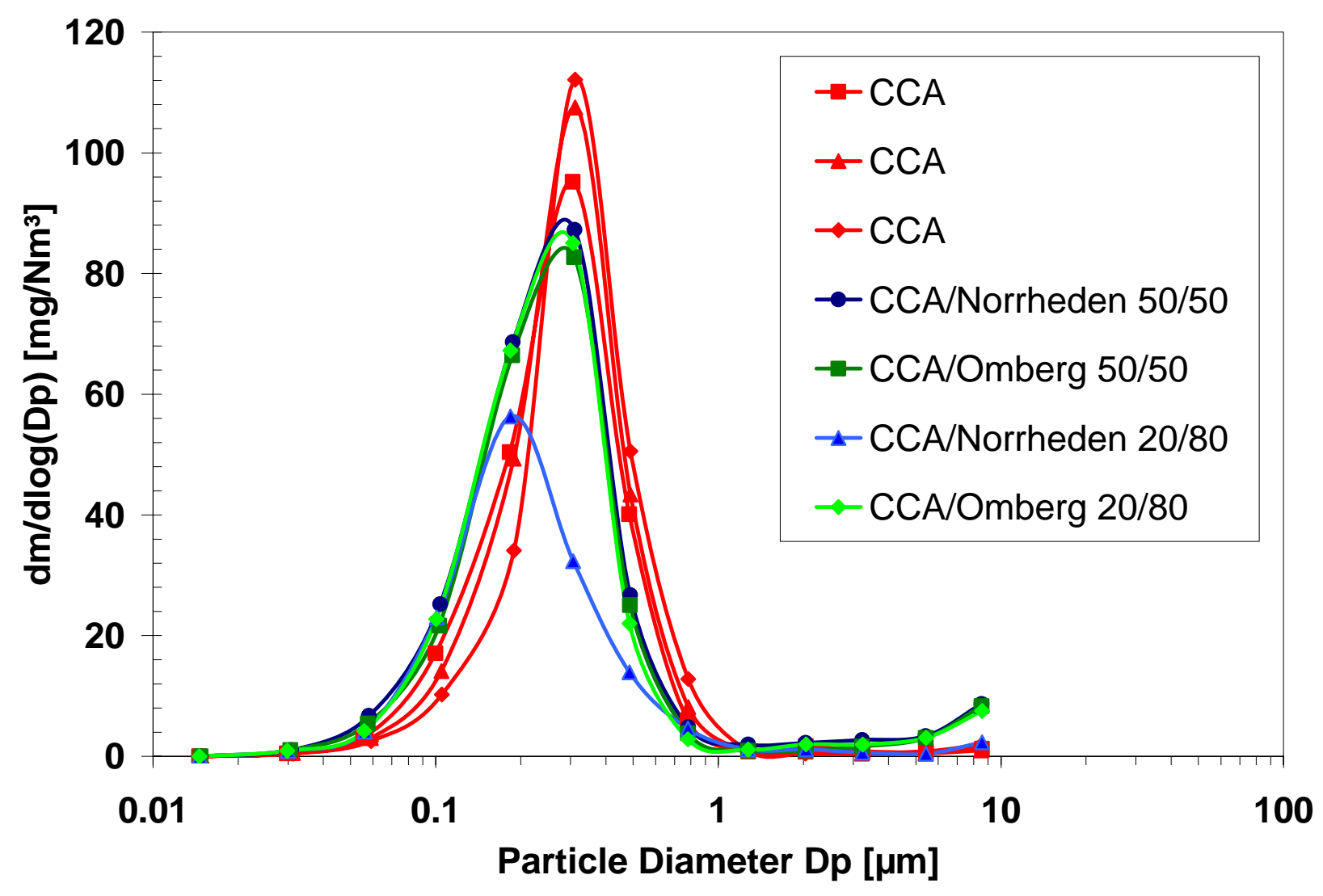

Figure SI 7. Particle mass size distributions for different fuels. 